\title{
Surgical outcome of primary intradural spinal arachnoid cysts: a series of 10 cases
}

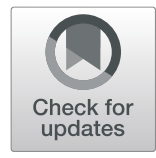

Essam Abdelhameed ${ }^{1 *}$ and Ahmed Ali Morsy ${ }^{2}$

\begin{abstract}
Background: Primary intradural spinal arachnoid cysts are rare pathologies of uncertain etiology and variable presentation from no symptoms to myelopathy or radiculopathy according to cord or root compression. MRI with diffusion and contrast differentiates them from many pathologies. There is a lot of debate regarding when to treat and how to treat such rare pathologies.

Objective: We present a series of 10 primary intradural arachnoid cysts and evaluate outcome after surgery.

Methods: This retrospective study includes patients having primary intradural spinal arachnoid cysts operated in two tertiary care centers from October 2012 till October 2019. Symptomatic cysts were subjected to microsurgical resection or outer wall excision and inner wall marsupialization under neurophysiological monitoring. The Japanese Orthopedic Association Score was used for clinical evaluation while MRI with contrast and diffusion was used for radiological evaluation before and after surgery.

Results: This series included 10 patients, 4 males and 6 females, with mean age of 40 years. Pain was the most common presentation. The most common location was dorsal thoracic region. Total excision was achieved in 2 cases and marsupialization in 8 cases.

All symptoms improved either completely or partially after surgery. No neurological deterioration or recurrence was reported during the follow-up period in this series.

Conclusion: Treatment of symptomatic primary intradural spinal arachnoid cysts should be microsurgical resection, when the cyst is adherent to the cord, microscopic fenestration can be safe and effective.
\end{abstract}

Keywords: Intradural spinal arachnoid cysts, Microscopic resection, Marsupialization

\section{Introduction}

Spinal arachnoid cysts are discrete pockets of CSF or CSF-like fluid found adjacent to normal CSF spaces and related to the spine. They are rare pathological entities and represent only $1-3 \%$ of spinal canal lesions [1]. They are classified according to anatomical location into intradural and extradural cysts [2], and few cases of intramedullary arachnoid cysts have also been reported [3, 4].

Many theories have been postulated to explain the origin of primary intradural spinal arachnoid cysts; the most popular is the origin from a thin midline arachnoid

\footnotetext{
* Correspondence: esam.hameed@yahoo.com

${ }^{1}$ Department of Neurosurgery, Faculty of Medicine, Tanta University Hospital,

Tanta University, Elgeish Street, Tanta 31257, Egypt

Full list of author information is available at the end of the article
}

membrane between the pia and arachnoid mater known as septum posticum, which is prominent at the level of thoracic spine, thus posterior thoracic location has been reported as the most common location for primary intradural spinal arachnoid cysts [5]. Another theory has suggested abnormal proliferation of arachnoid granulations during the embryonic period which leads to diverticula formation that develop later into cysts [6].

Secondary intradural cysts may also occur after trauma, hemorrhage, infection, or invasive spinal procedure as lumbar puncture. Inflammatory adhesions within the arachnoid may cause arachnoid webs which lead to CSF entrapment by a one-way valve mechanism within the webs [7]. 
Spinal arachnoid cysts have a wide range of clinical presentation, they may be asymptomatic and discovered incidentally, but sometimes they can cause myelopathy or radiculopathy due to cord or root compression; patients may complain of pain either back pain or radicular pain, and present by motor, sensory, or visceral problems [5].

MRI is the most sensitive and specific study for detecting a spinal arachnoid cyst; it clearly delineates the cysts, their location, and relation to neural tissues, septations, and loculations can also be visualized. The cyst contents appear isointense to CSF in all sequences. Contrast injection differentiates arachnoid from inflammatory and neoplastic cysts. MRI diffusion can differentiate arachnoid from dermoid cysts. Cine MRI flowmetry can be done in some cases to demonstrate CSF flow dynamics within the cyst [8]. CT myelography may show the cyst as filling defect [9].

Asymptomatic cysts should be treated conservatively with regular follow-up imaging as surgery is not recommended for most of incidentally discovered cysts. For symptomatic cysts, the ideal treatment is complete microsurgical resection which results in excellent outcome [1]. If the cyst wall is adherent to the spinal cord, marsupialization can be enough [10], but cyst aspiration alone is not recommended as it is associated with high recurrence rate. Cystoperitonel shunt can be done if microsurgical resection or marsupialization cannot be done [1].

Prognosis and surgical outcomes depend on multiple factors such as age, cyst location, duration of symptoms, degree of cord compression, and treatment method [11].

The literature contains few series or case reports and there is a lot of debate regarding diagnosis and treatment of such rare pathologies. We present our series and evaluate postoperative clinical and radiological outcome.

\section{Methods}

Patients population and preoperative evaluation

This retrospective study was based on prospectively collected data of patients with intradural spinal arachnoid cysts presented to neurosurgery departments at 2 tertiary care centers during the period from October 2012 to October 2019.

For all patients, MRI spine with different sequences including diffusion-weighted images and contrast enhancement was done to ensure the diagnosis of intradural arachnoid cysts, determine their location and relation to neural tissues, and if septations and loculations are present.

Management protocol was decided for all patients after careful analysis of clinical and radiological data by the entire team. For asymptomatic patients or patients with clinical presentation not attributed to their arachnoid cysts, conservative treatment and yearly follow-up imaging was decided and if symptoms arise, reevaluation of the cyst with MRI should be undertaken immediately. Only symptomatic spinal arachnoid cysts were subjected to surgery after informed consent and were included in this study. After ethical committee approval, patients' demographics, presenting symptoms, neurological examination data, and management details were collected.

\section{Surgical technique}

Posterior approach was done in all patients. Laminectomy, hemilaminectomy, or laminoplasty was performed according to operative plan under fluoroscopic guidance. All cysts were subjected to total microsurgical resection or outer wall excision and inner wall marsupialization under neurophysiological monitoring for somatosensory (SSEP) and motor evoked potentials (MEP). All wounds were closed tightly in layers after good hemostasis with application of fibrin glue in some cases and without leaving drains to avoid postoperative CSF leakage.

\section{Postoperative course and follow-up}

All patients were evaluated clinically at the first postoperative day and before hospital discharge. Regular follow-up was at 1,3 , and 6 months postoperative then annually for evaluation of clinical outcome.

The Japanese Orthopedic Association Score (JOAS) was used for clinical evaluation in all patients before and after surgery. Pain was given score according to severity where 0 means continuous severe pain, 1 means occasional severe pain, 2 means occasional mild pain, and 3 means no pain. Motor, sensory, and visceral disturbances were given scores according to severity where 0 means severe disturbance, 1 means mild disturbance, and 2 means normal. Items of daily activity affected in the form of turn over while lying, standing, washing, leaning forwards, sitting about $1 \mathrm{~h}$, lifting heavy objects and walking were given scores according to degree of limitation from 0 to 2 where 0 means severe limitation, 1 means mild and 2 means no limitation of daily activity. Pre and postoperative scores were recorded and analyzed.

All operated patients were subjected to postoperative MRI at 3 and 6 months visit then on yearly basis to evaluate cord or root decompression and exclude cyst recurrence.

\section{Results}

Twenty-six patients having intradural spinal arachnoid cysts were presented to our institutes during the study period. Sixteen patients of them were considered asymptomatic, only follow-up was decided and these patients were excluded from the study. Ten patients (4 males and 6 females) had symptomatic intradural cysts and 
included in our study. Their age ranged from 3 years to 59 years with mean age of 40 years. Nine patients had back pain at different levels of the spine. Sensory manifestations in the form of severe bilateral lower limb numbness were present in one patient, while motor weakness was present in three patients. Three patients had restriction of daily activity in the form of spasticity and gait disturbance and one patient presented with visceral problems in the form of mild urinary incontinence. Full description of clinical presentation and JOAS of each patient is shown in (Table 1).

The cyst was located in the thoracic region in nine patients, while it was cervical in one patient. The relation to the cord was ventrolateral in two patients and dorsal in eight patients.

Duration of symptoms ranged from 1 to 16 months with mean duration of 7.2 months. Laminectomy was done in 5 cases, hemilaminectomy in 2 cases, and laminoplasty in 3 cases. Pain improved postoperative completely in 5 patients and partially in 4 patients. Motor power improved completely in all patients and the patient who had sensory manifestations showed partial improvement. Restriction of daily activity was minimized in all patients. No neurological deterioration was encountered in this series (Table 1).

The cyst was completely resected in two patients and was marsupialized in eight patients.

No dural graft was required, and no CSF leakage or infection was reported in our study. Hospital stay ranged from 1 to 4 days with mean of 2.3 days. Mean follow-up period was 41.2 months (range 6-84 months) and no recurrence had been reported in this series.

\section{Discussion}

Spinal arachnoid cysts are rare pathologies which are asymptomatic in some cases or even missed or undiagnosed in some symptomatic cases, that is why the literature contains a few case reports or small series of such cases [1]. The aim of this study is to introduce our series of primary intradural spinal arachnoid cysts and to evaluate management outcomes.

MRI with different sequences including contrast administration is the gold standard investigation, it can differentiate a spinal arachnoid cyst from a wide variety of cystic spine lesions, and it can also clearly demonstrate the exact location of the cyst, septations or loculations, and degree of cord compression. CT myelography explore spinal arachnoid cysts as filling defects. In some cases, rapid and slow filling cysts may be missed in CT myelography. In case of rapid filling cysts, the cyst merges with the subarachnoid space rapidly, but the dye will be absorbed rapidly from the subarachnoid space and retained within the cyst, so the dye can be demonstrated within the cyst in delayed CT myelography. In case of slowly filling cysts delayed entry of the dye can be demonstrated in delayed CT myelography [9].

Spinal arachnoid cysts have wide range of differential diagnosis, they should be differentiated from neuroenteric cysts which usually occur anterior to the spinal cord in the cervicothoracic region and sometimes associated with septic meningitis, they have thick wall during surgery. Perineural cysts are usually sacral and related to nerve roots. Synovial cysts are usually low lumbar (motion segments) and related to facet joints. Dermoid cysts have reversed MRI signals $\mathrm{T} 1$ hyperintense and T2

Table 1 Patient data

\begin{tabular}{|c|c|c|c|c|c|c|c|c|c|c|c|}
\hline $\mathrm{Pt}$ & Age & Sex & Presentation & $\begin{array}{l}\text { Pre } \\
\text { JOAS }\end{array}$ & position & Level & $\begin{array}{l}\text { Duration } \\
\text { symptom }\end{array}$ & Approach & Result & $\begin{array}{l}\text { Po } \\
\text { JOAS }\end{array}$ & $\begin{array}{l}\text { Rad } \\
\text { outcome }\end{array}$ \\
\hline 1 & 40 & Female & $\begin{array}{l}\text { Back pain } \\
\text { RDA }\end{array}$ & $\begin{array}{l}1 \\
6 / 14\end{array}$ & Dorsal & D3-D5 & $16 \mathrm{M}$ & Laminectomy & Excision & $\begin{array}{l}3 \\
12 / 14\end{array}$ & Cord decompression \\
\hline 2 & 58 & Female & $\begin{array}{l}\text { Back pain } \\
\text { Motor }\end{array}$ & $\begin{array}{l}1 \\
0\end{array}$ & Dorsal & D1-D6 & $2 M$ & Laminoplasty & marsupialization & $\begin{array}{l}2 \\
2\end{array}$ & Cord decompression \\
\hline 3 & 21 & Female & Back pain & 0 & Dorsal & D2-D6 & $12 \mathrm{M}$ & Laminectomy & Marsupialization & 2 & Cord decompression \\
\hline 4 & 44 & Female & $\begin{array}{l}\text { Back pain } \\
\text { Sensory }\end{array}$ & $\begin{array}{l}1 \\
0\end{array}$ & Dorsal & D4-D8 & $14 \mathrm{M}$ & Laminectomy & Marsupialization & $\begin{array}{l}3 \\
1\end{array}$ & Cord decompression \\
\hline 5 & 3 & Male & Motor & 1 & V.lat. & C1-D3 & $3 M$ & Laminoplasty & Marsupialization & 2 & Cord decompression \\
\hline 6 & 51 & Male & $\begin{array}{l}\text { Back pain } \\
\text { RDA }\end{array}$ & $\begin{array}{l}0 \\
5 / 14\end{array}$ & Dorsal & D4-D7 & $6 \mathrm{M}$ & $\begin{array}{l}\text { Hemi } \\
\text { laminectomy }\end{array}$ & Marsupialization & $\begin{array}{l}3 \\
14 / 14\end{array}$ & $\begin{array}{l}\text { Cord } \\
\text { decompression }\end{array}$ \\
\hline 7 & 57 & Male & $\begin{array}{l}\text { Back pain } \\
\text { Motor }\end{array}$ & $\begin{array}{l}1 \\
1\end{array}$ & V.lat. & D5-D9 & $1 \mathrm{M}$ & Laminectomy & Marsupialization & $\begin{array}{l}3 \\
2\end{array}$ & Cord decompression \\
\hline 8 & 36 & Female & $\begin{array}{l}\text { Back pain } \\
\text { Visceral }\end{array}$ & $\begin{array}{l}1 \\
1\end{array}$ & Dorsal & D10-L1 & $8 M$ & $\begin{array}{l}\text { Hemi } \\
\text { laminectomy }\end{array}$ & Excision & $\begin{array}{l}3 \\
1\end{array}$ & Cord decompression \\
\hline 9 & 59 & Female & Back pain & 0 & Dorsal & D4-D7 & $6 M$ & Laminoplasty & Marsupialization & 2 & Cord decompression \\
\hline 10 & 34 & Male & $\begin{array}{l}\text { Back pain } \\
\text { RDA }\end{array}$ & $\begin{array}{l}1 \\
7 / 14\end{array}$ & Dorsal & D4-D5 & $4 M$ & Laminectomy & Marsupialization & $\begin{array}{l}2 \\
12 / 14\end{array}$ & Cord decompression \\
\hline
\end{tabular}


hypointense. Epidermoid cysts are isointense to CSF but can be differentiated by diffusion-weighted images. Cysticercosis cysts usually have wall calcifications. Inflammatory and neoplastic cysts usually enhance after contrast injection [9].

In this study, we used MRI only in diagnosis and surgical planning for all cases because we have advanced MRI devices (1.5 and 3 Tesla) with high-resolution images. The high sensitivity and specificity of MRI, easy interpretation of images, and being non-invasive maneuver replaced the need for CT myelography which necessitate intrathecal dye injection. Previous similar studies reported that MRI was enough in diagnosis and follow-up of their patients as in our series $[10,12]$. On the contrary, Fam et al. reported in their series that MRI was not conclusive in 6 cases out of 22 patients, for whom CT myelography was done. Three patients proved to have intradural spinal arachnoid cysts and one patient had extradural cyst with definite dural defect communicating the cyst to the subarachnoid space [13].

Females presented 1.5:1 ratio in our series which is matching with the previous reports in the literature. Sadek et al. reported female to male ratio 1.8:1 in their series of 17 patients [5] and Fam et al. reported a ratio of 3:1 in their series of 22 patients [13]. The mean age in our series was 40 years; Sadek et al. in their series also reported mean age of 58.2 years [5]. Despite the congenital theory which is supposed to be the origin of spinal arachnoid cysts and expectations of such pathologies at earlier ages, this mean age of patients could be attributed to the long time spent by these cysts to increase in size and longer time to produce symptoms.

The series of Sadek et al. included only primary intradural arachnoid cysts and reported 100\% location in the dorsal thoracic region [5], supporting the theory suggesting origin of intradural spinal arachnoid cysts from septum posticum which is more prominent at the same location. We found the predominant location in our series is the dorsal (posterior) thoracic 90\% which is matching with the series of Kriss and Kriss 80\% [14]; a 3 -year-old child had a cervical ventrolateral cyst (Fig. 1) which is against the theory of septicum posticum origin and may be in favor of the theory of origin from abnormal proliferation of arachnoid granulations during the embryonic period leading to formation of diverticula that develop into cysts. Many theories have been
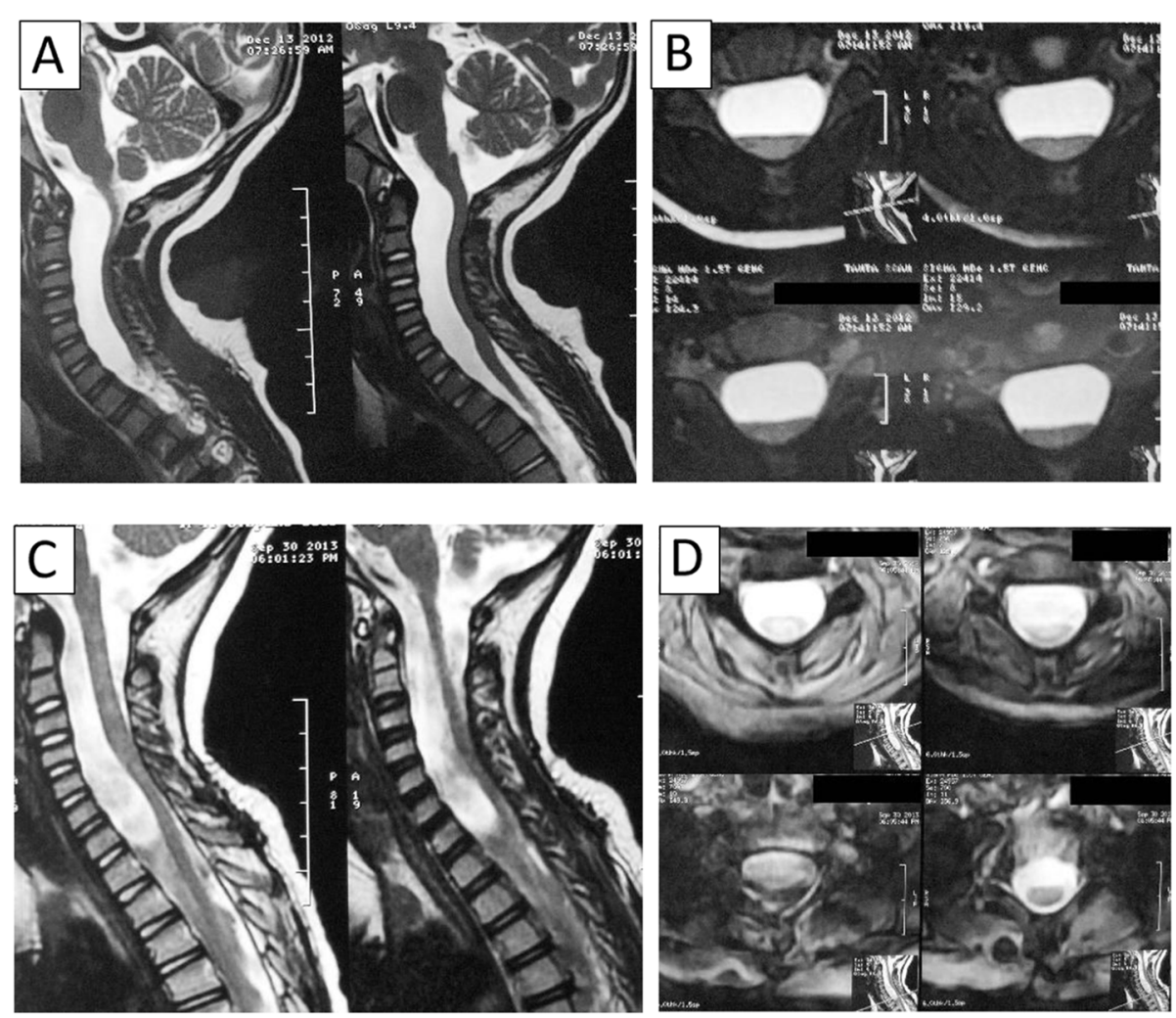

Fig. 1 Case 1: 3-year-old male child presented by delayed motor milestones; clinical examination revealed quadriparesis. Preoperative MRI (a) sagittal T2 and (b) axial T2 showing ventral cervicothoracic spinal arachnoid cyst compressing the cord and pushing it posteriorly. The patient was operated for laminoplasty and cyst wall marsupialization. Follow-up MRI 3 months later (c) sagittal T2 and (d) axial T2 showing cord decompression and return to original position. The patient was clinically and radiologically stable during annual follow-up 
postulated to explain the origin of spinal arachnoid cysts but till the moment nothing proved to be the direct cause for spinal arachnoid cyst formation [5].

The approach in our series varied from laminoplasty, hemilaminectomy to formal laminectomy according to cyst location, size, cord compression, and surgeon experience. We depend on the fact that laminectomy does not affect stability of the dorsal spine which is enforced by the rib cage $[5,15,16,17]$ no instrumental fixation was needed in any of our cases.

Clinical outcome of our series revealed complete improvement of pain in five patients and partial improvement in four patients. Complete improvement of motor power in all patients. The only patient who had sensory manifestations showed partial improvement. Daily activity improved in all patients. Eroglu et al. concluded that pain and weakness were the most likely to improve while sensory manifestations were the least likely to improve [1].

The aim of surgery was cord decompression which was achieved in all cases through microsurgical resection in two cases and marsupialization in eight cases; marsupialization was preferred when the inner layer was adherent to the cord making total excision risky. Viswanathan et al. also recommended cyst wall fenestration and partial excision in case of intradural arachnoid cysts to avoid cord manipulation and possible postoperative neurological deficit [10].

One of our cases (Fig. 2) had a recurrent intradural cyst after history of being operated for cystoperitoneal shunt in another center. MRI showed multiloculaed intradural cyst with significant cord compression, X-ray dorsal spine and X-ray abdomen and pelvis showed both spinal and peritoneal ends of cystoperitoneal shunt are in place. The patient was operated for microscopic excision of the outer cyst wall, fenestration of the septa and marsupialization of the inner wall. Shunt tube was left in place because no extra work was needed to leave it in its sound position, and it can decrease the incidence of postoperative CSF leakage from the wound and late cyst recurrence. The patient improved clinically after surgery, and follow-up MRI showed cord decompression.

No post-operative neurological deterioration; CSF leakage or infection had been observed in our series during the follow-up period. No cyst recurrence had been encountered in this series even in marsupialized cysts, Krings et al. reported recurrence in one case where they only closed the dural defect without cyst excision, and this patient was operated again with
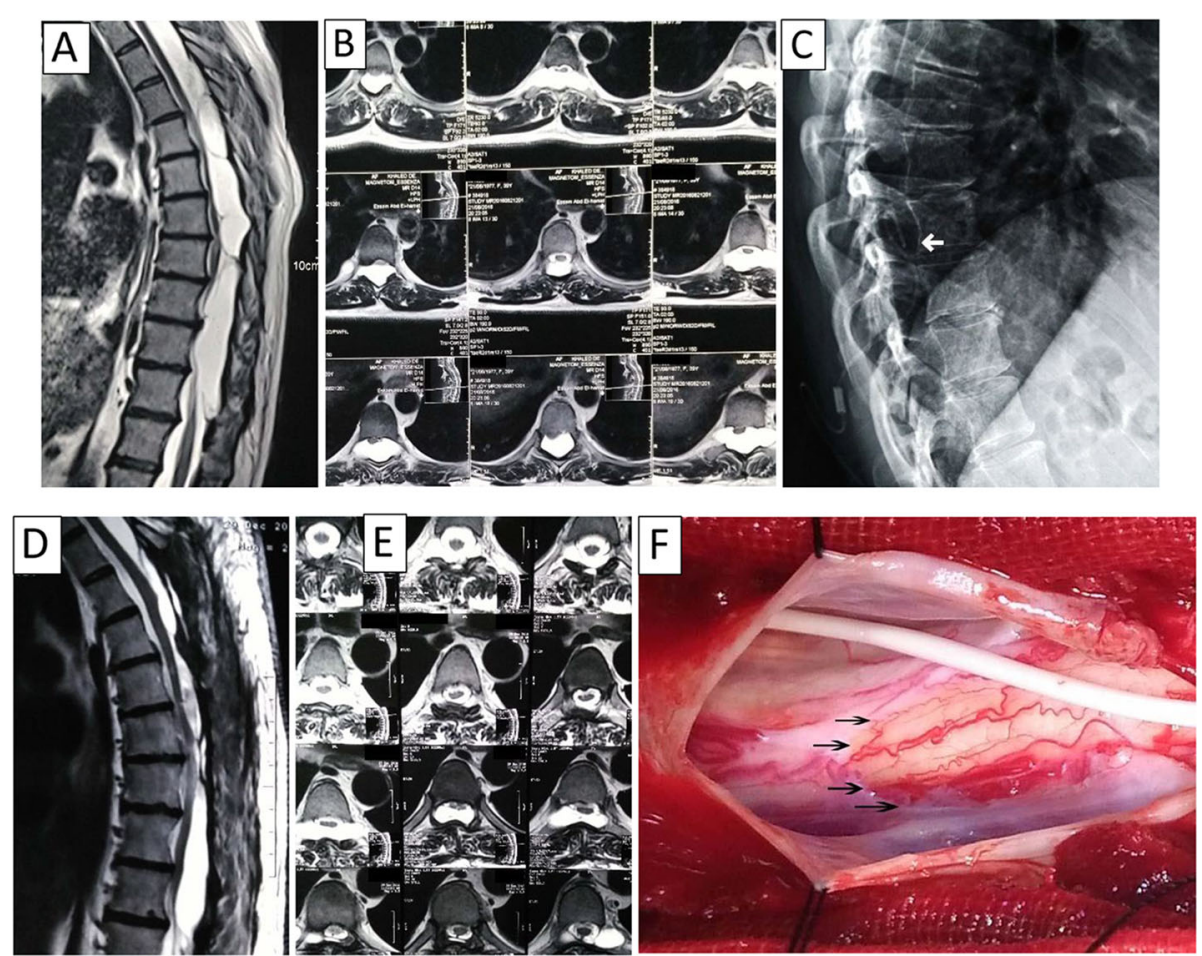

Fig. 2 Case 2: 34-year-old male presented by persistent back pain and moderate restriction of daily activity after history of being operated for cystoperitoneal shunt in another center. Initial MRI pictures before the first surgery were not available, plain X-ray on shunt tube (white arrow, c) showed both spinal and peritoneal ends in place, sagittal and axial T2 MRI (a, b) showing multilocular dorsal thoracic cyst compressing the cord. The patient was operated for microscopic excision of the outer cyst wall, fenestration of the septa, and marsupialization of the inner wall (black arrows, $\mathbf{f}$ ), shunt tube was left in place (f). The patient improved immediately after surgery and follow up MRI sagittal and axial T2 (d, e) showed cord decompression. No cyst recurrence was observed during annual follow-up period 
total resection of the cyst, all symptoms improved after the second operation [9].

\section{Study limitations}

The limitations of this study are those inherent to retrospective nature with small populations. We believe that greater number of cases with longer follow-up period will have more reliable results for future research of such rare pathology.

\section{Conclusion}

Intradural spinal arachnoid cysts are rare pathologies and often asymptomatic requiring no treatment. Treatment of symptomatic cysts should be microsurgical excision under neurophysiological monitoring. When the cyst is adherent to the cord, microscopic fenestration and marsupialization can be safe and effective. Cystoperitoneal shunt should not be the first therapeutic option; it can be done when microscopic excision or fenestration are not applicable.

\section{Abbreviations}

RDA: Restriction of daily activity; V.Lat: Ventrolateral; Pre JOAS: Preoperative Japanese Orthopedic Association Score; Po: Postoperative

\section{Acknowledgements}

Not applicable

\section{Authors' contributions}

Both "EA" and "AM" equally participated in operating patients, data collection, data analysis, and scientific writing. Both authors read and approved the final manuscript.

\section{Funding}

The research did not receive any specific grant from funding agencies in the public, commercial, or not-for-profit sectors.

\section{Availability of data and materials}

The datasets used and/or analyzed during the current study are available from the corresponding author on reasonable request.

\section{Ethics approval and consent to participate}

Approved from the research ethics committee, Faculty of Medicine, Tanta University (reference number 33766/04/20 obtained in April 2020). Consent for participation was not applicable as the study is retrospectively performed.

\section{Consent for publication}

Not applicable.

\section{Competing interests}

None.

\section{Author details}

'Department of Neurosurgery, Faculty of Medicine, Tanta University Hospital, Tanta University, Elgeish Street, Tanta 31257, Egypt. ${ }^{2}$ Department of Neurosurgery, Faculty of Medicine, Zagazig University, Zagazig, Egypt.

Received: 19 August 2020 Accepted: 15 February 2021

Published online: 20 March 2021

\section{References}

1. Eroglu U, Bozkurt M, Kahilogullari G, et al. Surgical Management of Spinal Arachnoid Cysts in Adults. World Neurosurg. 2019;122:e1146-52.

2. Nabors MW, Pait TG, Byrd EB, et al. Updated assessment and current classification of spinal meningeal cysts. J Neurosurg. 1988;68(3):366-77.
3. Lmejjati M, Aniba K, Haddi M, et al. Spinal intramedullary arachnoid cyst in children. Pediatr Neurosurg. 2008;44:243-6.

4. Medved F, Seiz M, Baur MO, et al. Thoracic intramedullary arachnoid cyst in an infant. J Neurosurg Pediatr. 2009;3:132-6.

5. Sadek AR, Nader-Sepahi A. Spinal Arachnoid Cysts: Presentation, management and pathophysiology. Clin Neurol Neurosurg. 2019;180:87-96.

6. Klekamp J. A New Classification for Pathologies of Spinal Meninges_-Part 2: Primary and Secondary Intradural Arachnoid Cysts. Neurosurg. 2017;81(2): 217-29.

7. Fortuna A, La Torre E, Ciappetta P. Arachnoid diverticula: A unitary approach to spinal cysts communicating with the subarachnoid space. Acta neurochir. 1977;39(3-4):259-68.

8. Garg K, Borkar SA, Kale SS, Sharma BS. Spinal arachnoid cysts - our experience and review of literature. British J Neurosurg. 2017;31(2):172-8.

9. Krings T, Lukas R, Spetzger U, et al. Diagnostic and Therapeutic Management of Spinal Arachnoid Cysts. Acta Neurochirurgica. 2001;143(3): 227-35.

10. Viswanathan VK, Manoharan SR, Do H, et al. Clinical and Radiologic Outcomes After Fenestration and Partial Wall Excision of Idiopathic Intradural Spinal Arachnoid Cysts Presenting with Myelopathy. World Neurosurg. 2017;105:213-22.

11. Kendall BE, Valentine AR, Keis B. Spinal arachnoid cysts: Clinical and radiological correlation with prognosis. Neuroradiol. 1982;22(5):225-34.

12. Wang MY, Levi AD, Green BA. Intradural spinal arachnoid cysts in adults. Surg Neurol. 2003;60(1):49-55.

13. Fam MD, Woodroffe RW, Helland L, et al. Spinal arachnoid cysts in adults: diagnosis and management. A single-center experience. J Neurosurg: Spine. 2018;29(6):711-9.

14. Kriss TC, Kriss VM. Symptomatic spinal intradural arachnoid cyst development after lumbar myelography. Case report and review of the literature. Spine. 1997;22(5):568-72.

15. Abumi KU, Panjabi MM, Kramer KM, et al. Biomechanical evaluation of lumbar spinal stability after graded facetectomies. Spine. 1990;15(11):1142-7.

16. Aizawa $\mathrm{T}$, Sato $\mathrm{T}$, Ozawa $\mathrm{H}$, et al. Sagittal alignment changes after thoracic laminectomy in adults. Journal of Neurosurgery: Spine. 2008:8(6):510-6.

17. Chen $\mathrm{XQ}$, Yang $\mathrm{HL}$, Wang GL, et al. Surgery for thoracic myelopathy caused by ossification of the ligamentum flavum. J Clin Neurosci. 2009;16(10):131620.

\section{Publisher's Note}

Springer Nature remains neutral with regard to jurisdictional claims in published maps and institutional affiliations.

\section{Submit your manuscript to a SpringerOpen ${ }^{\circ}$ journal and benefit from:}

- Convenient online submission

- Rigorous peer review

- Open access: articles freely available online

- High visibility within the field

- Retaining the copyright to your article

Submit your next manuscript at $\boldsymbol{\nabla}$ springeropen.com 